\title{
An Investigation to Assess the Cause of Accident due to Flyrock in an Opencast Coal Mine: A Case Study
}

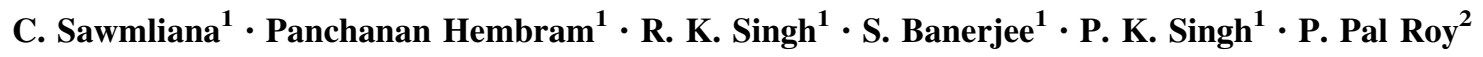

Received: 9 January 2020/Accepted: 11 April 2020/Published online: 24 April 2020

(C) The Author(s) 2020

\begin{abstract}
The paper deals with the investigation carried out to find out the possible reason of the flyrock incident causing fatality of one person at Bhurkunda 'Á' Colliery of Central Coalfields Limited (CCL). The flying fragment travelled up to $280 \mathrm{~m}$ from the blasting source causing the accidental death. The blasts were conducted in overburden rock strata consisting of medium grained sandstone and shale. The blasthole diameter used in the blast was $160 \mathrm{~mm}$, and the average hole depth was $6.0 \mathrm{~m}$. Site mixed emulsion (SME) explosive was used in the blast, and explosive charge per hole was $50.00 \mathrm{~kg}$. Non-electric initiation systems were used for in-hole explosive and surface hole-to-hole initiations. The design parameters used in the blast were thoroughly analyzed using blast simulation software to check any anomaly in the blast design viz. sequence of hole firing, success rate of burden movement, maximum charge per delay fired within $8 \mathrm{~ms}$ windows, etc. The different flyrock fragments prediction models were used to assess the maximum possible travel distance of the flying in the blast. A synonymous blast was also conducted in the mines to replicate the blast where flyrock accident occurred. All the blasting events were recorded and monitored using a digital video camera. The simulation results of the blast showed the success rate of burden relief more than $80 \%$ with sufficient delay intervals for the rock movement during the blast. The maximum possible travel distance of flying fragments based on different flyrock prediction models was $227 \mathrm{~m}$. In the synonymous blast,
\end{abstract}

C. Sawmliana

csla_cimfr@yahoo.com

1 CSIR-Central Institute of Mining and Fuel Research (CSIRCIMFR), Dhanbad, India

2 B C Roy Engineering College, Durgapur, India only vertical throws of the flying fragments up to $70 \mathrm{~m}$ (approximate) height were observed. It was difficult to find out the exact cause of flyrock incident. However, based on the detailed investigation, it was concluded that the possible cause of flying fragments travelling up to a distance of $280 \mathrm{~m}$ could be due to the presence of a weak zone in the rock strata.

Keywords Blasting · Flyrock · Prediction model · Explosive $\cdot$ Safety

\section{Introduction}

In blasting operations, flyrock (uncontrolled flying fragment) is one of the main causes of accident. The other blasting impacts to the surroundings such as ground vibration, noise (air overpressure/air-blast), fumes and dust can hardly cause direct injury and fatality to human, although they may cause structural damage and nuisance to the nearby residential houses and habitats. The accident due to flyrock remains one of the major contributors of fatal and serious accidents in opencast mines. The 'Danger Zone' as given in Coal Mine Regulations [1] has already been increased from 300 to $500 \mathrm{~m}$ in the new Coal Mines Regulation [2] [Reg. 196 (2) (b)] to avert flyrock-related accidents in opencast coal mines. There are many reasons for flyrock causes and associated accidents during blasting in opencast mines. Overcharging of holes with explosive, less stemming length, improper stemming, less burden, undercut, overcut/break-back/end-back due to previous blasting, presence of loose material in the strata, cavities, improper initiation sequence among others are the common causes of flyrock in bench blasting. The reasons for accident due to flyrock also include failure to evacuate the area, 
failure to take shelter, failure to communicate, taking unsafe shelter, etc. It is important to consider all the possible causes flyrock incidence right from the loading of holes with explosives and up to clearance of the blasting area.

In Bhurkunda 'A' Colliery of Central Coalfields Limited (CCL), in Ramgarh District of Jharkhand State, a fatal accident occurred on 5th April, 2017, where one blasting helper employed in the mine died due to hit by a flying fragment generated from the blasting operation. The accident took place when blasting was conducted in an overburden bench using site mixed emulsion (SME) explosives. Blasthole diameter was $160 \mathrm{~mm}$, and depths of holes were $6.0 \mathrm{~m}$. Burden and spacing were $3.5 \mathrm{~m}$ and $4.0 \mathrm{~m}$, respectively. The explosive charge per hole was $50.00 \mathrm{~kg}$ where shock tube (non-electric) initiating system was used for in-hole explosive initiation as well as surface hole-tohole initiation. One of the flying fragments generated from the blast travelled up to a distance of $280 \mathrm{~m}$ and hit the blasting helper causing serious bodily injured and died on the spot.

As per the design and connection of blast holes, flying fragments should not have travelled for such along distance of $280 \mathrm{~m}$ from the place of firing especially when the stemming was maintained as 3.5 to $3.8 \mathrm{~m}$ in each hole. The reason for flying fragments travelling to such a long distance from the place of blasting which resulted into the fatal accident was investigated. The nature of rock deposits at the blasting bench where flyrock incident occurred was studied. A synonymous blast was also conducted to replicate the actual blast in which flyrock occurred. The different flyrock prediction models were used to assess the possible distance of flyrock travel for that blast. The detailed investigation carried out for the possible causes of flyrock occurrence, thereby causing fatal accident in the mine is presented in this paper.

\section{Flyrock Prediction Models}

There are many flyrock prediction models developed by different researchers. Most of the predictions for distance of flying fragments during the blasts have been made based on the empirical methods. Some researchers also tried to predict flyrock using the advanced computational techniques such as artificial neural networks, fuzzy logic, support vector machines. However, it is difficult to predict the exact distance of flyrock as there are many factors and parameters involved in generation and propagation of flying fragments during a blast. Some of the empirical models for flyrock prediction in bench blasting are reviewed in this section.
Lundborg et al. [3] used semi-empirical approach to estimate flyrock throw distance. The prediction model for maximum flyrock range is based on charge diameter as:

$L_{\max }=260 D^{2 / 3}$

$T_{\mathrm{b}}=0.1 \times D^{2 / 3}$

where $L_{\max }$ is the maximum flyrock range $(\mathrm{m}), T_{\mathrm{b}}$ is the size of the rock fragment $(\mathrm{m}), d$ is the diameter of explosive (inch).

Richard and Moore [5] used burden (B), stemming length (ST), drill hole angle $(\theta)$, explosive charge weight per meter length $(\mathrm{kg} / \mathrm{m})$, gravitational constant $(\mathrm{g})$ and site constant (k) to estimate flyrock range for different flyrock mechanisms as given in Table 1.

McKenzie [4] developed equations to predict maximum flyrock range and particle size for achieving the maximum range for blasts of varying rock density, blasthole diameter, explosive density and the state of confinement. The maximum flyrock range is given by:

$L_{\max }=11 \times \mathrm{SDB}_{\mathrm{m}}^{-2.167}\left(\frac{\emptyset}{F_{\mathrm{s}}}\right)^{0.667}$

where $L_{\max }$ is the maximum flyrock range (m), $\mathrm{SDB}_{m}$ is the maximum scale depth of burial (metric), $\phi$ is the blasthole diameter $(\mathrm{mm})$ and $F_{\mathrm{S}}$ is the shape factor (usually between 1.1 and 1.3).

The scale depth/distance of burial of the explosive charge is given by the following:

$\mathrm{SDB}_{\mathrm{m}}=\frac{S t+0.0005(m \times \emptyset)}{0.00923\left(m \times \emptyset^{3} \times \rho_{e}\right)^{0.33}}$

where $S t$ is the stemming length (m), $m$ is the charge length as multiple of hole diameter (maximum 8 for blasthole diameter less than $100 \mathrm{~mm}$ and 10 for blasthole diameter equal to or more than $100 \mathrm{~mm}, \phi$ is the blasthole diameter $(\mathrm{mm})$ and $\rho_{e}$ is the explosive density $(\mathrm{g} / \mathrm{cc})$.

The equation to estimate the size of particle capable of achieving maximum projection distance is given by:

$x_{\mathrm{f}}=2.82 \times\left(\frac{2.6}{\rho_{\mathrm{r}}}\right) \times \mathrm{SDB}_{\mathrm{m}}^{-2.167} \times \emptyset^{0.667} \times F_{\mathrm{s}}^{0.333}$

where $x_{f}$ is the particle size $(\mathrm{m}), \rho_{r}$ is the rock density (g/ cc).

In order to incorporate error in stemming during the actual operation, the correction for stemming length to acquire $95 \%$ of the stemming columns is given by:

$S t_{95}=S t_{\text {avg }}-1.64 \times \sigma_{\text {sd }}$

where $S t_{\mathrm{avg}}$ is the average stemming length (m), $\sigma_{\mathrm{sd}}$ is the standard deviation of the stemming length (m), $S t_{95}$ is the $95 \%$ value of the stemming length $(\mathrm{m})$. 
Table 1 Flyrock prediction model (after Little [6])

\begin{tabular}{ll}
\hline Mechanisms of flyrock & Prediction model \\
\hline Rifling & $L_{\max }=\frac{k^{2}}{g}\left(\frac{\sqrt{m}}{S \mathrm{~T}}\right)^{2.6} \sin 2 \theta_{0}$ \\
Cratering & $L_{\max }=\frac{k^{2}}{g}\left(\frac{\sqrt{m}}{\mathrm{ST}}\right)^{2.6}$ \\
Face bursting & $L_{\max }=\frac{k^{2}}{g}\left(\frac{\sqrt{m}}{B}\right)^{2.6}$ \\
\hline
\end{tabular}

Raina et al. [7] developed a flyrock predictor model based on the impact (i) and time $(\Delta t)$ over which the impulse is received by the flyrock from the high pressure gases generated after detonation of explosives. Based on this pressure-time model, the distance travelled by a flyrock can be estimated with the help of the following equation for projectile motion:

$R=\frac{V_{0}^{2} \sin 2 \theta}{g}$

where $V_{0}$ is the initial velocity $(\mathrm{m} / \mathrm{s}), g$ is the acceleration due to gravity $\left(9.81 \mathrm{~m} / \mathrm{s}^{2}\right)$.

Assuming that a flyrock is at rest being launched into air by the pressure acting upon it over a period $\Delta t$, the initial velocity component can thus be evaluated as:

$V_{0}=a \Delta t$ or $V_{0}=\frac{P_{\mathrm{bc}} \times A}{m} \times \Delta t$

Thus, the distance of flyrock estimated from the $P_{\mathrm{bc}}-t$ method can be given as:

$R_{\mathrm{fpt}}=\frac{\left[\left(P_{\mathrm{bc}} \pm \Delta P_{\mathrm{t}}\right)^{2} A^{2} \Delta t^{2}\right] \times \operatorname{Sin} 2 \theta}{g \times m^{2}}$

where $R_{\mathrm{fpt}}$ is the distance of flyrock (m) estimated, $P_{\mathrm{bc}}$ is the pressure acting on the flyrock fragment at escape, $\Delta P_{t}$ is the extrapolation of pressure for probe distance with respect to burden (B), when pressure probe distance $>\mathrm{B}$, then extrapolated $P_{\mathrm{bc}}=P_{\mathrm{bc}}+\Delta P_{\mathrm{t}}$, and when pressure probe distance $<\mathrm{B}$, then extrapolated $P_{\mathrm{bc}}=P_{\mathrm{bc}}-\Delta P_{\mathrm{t}}$, A is the area of flyrock fragment $\left(\mathrm{m}^{2}\right), \Delta t$ is the time of application of the pressure on the flyrock fragment, $\mathrm{m}$ is the mass of the flyrock fragment $(\mathrm{kg})$.

In order to predict the flyrock range based on Eq. 9, the measurement of pressure-time history has to be carried out in actual field conditions using pressure probe.

\section{The Investigational Works}

Bhurkunda Colliery is one of the oldest collieries of BarkaSayal area in South Karanpura Coalfields. The colliery was opened in the year 1924 under the ownership of State Railways. Subsequently, it was taken over by the National Coal Development Corporation (NCDC) in the year 1956.
It was again taken over by Central Coalfields Limited (A subsidiary of Coal India Limited) in the year 1976. Bhurkunda colliery consists of Bhurkunda 'A' colliery and Bhurkunda 'B' colliery. Bhurkunda 'A' Colliery consists of Quarry No. 3 and Balkudra Outsourcing patch, and Bhurkunda ' $\mathrm{B}$ ' Colliery consists of all the underground mines. The mine is located at a distance of $19 \mathrm{~km}$ from Ramgarh Cant. and connected by metalled road and railway route. Other road directly leads to Ranchi through Patratu Dam-Pithoria. Nearest railway station is Bhurkunda Railway station, $3 \mathrm{~km}$ from the project office.

On 5th April 2017, one fatal accident of a blasting helper took place at Bhurkunda 'A' colliery (Balkudra Quarry of Outsourcing Patch) by flying fragment during blasting operations. The blasting helper was engaged in charging of shot holes as well as evacuation of persons from the danger zone so that blasting could be done safely. However, after blasting at about $2.15 \mathrm{pm}$, the person received serious injury due to badly hit by a flying fragment at a distance of $280 \mathrm{~m}$ from the blasting site and died on the spot soon after. During the accident, the person was taking bath in the nearby river and did not wear helmet and did not take any shelter. The location of the blast and place of flyrock accident are shown in Fig. 1.

\section{Blast Design Parameters used in the Accidental Blast}

The blasting operation was conducted at Overburden (OB) Bench No. 3 and the strata consists of sandstone and shale. The total number of holes blasted was 115 , drilled in two patches in the same bench as shown in Fig. 2. The total number of holes in Patch-1 was 45 and in Patch-2, it was 70. The distance between the two patches was 12 to $15 \mathrm{~m}$. As per the blast design submitted by the mine management, the diameter of blastholes was $160 \mathrm{~mm}$ with the average hole depth of $6.0 \mathrm{~m}$. Burden and spacing were $3.5 \mathrm{~m}$ and $4.5 \mathrm{~m}$, respectively. Site mixed emulsion (SME) explosive of M/s Solar India Industries Limited (BE-101) was used. The density of explosive after gassing was $1.10 \mathrm{~g} / \mathrm{cc}$. The explosive charge per hole varied from 50.00 to $55.00 \mathrm{~kg}$, and a single column charge was used in all the holes. Drill cutting was used as stemming materials and top stemming column length of more than $3.5 \mathrm{~m}$ was used for all the holes. No muffling was done. The explosive charges in the holes were initiated with $250 \mathrm{~ms}$ DTHs and $150 \mathrm{gm}$ weight of emulsion booster. Diagonal firing pattern using $17 \mathrm{~ms}$ along the first row of holes and $42 \mathrm{~ms}$ TLDs between the rows were used. The total explosive charge was $5750.00 \mathrm{~kg}$ of SME and $17.25 \mathrm{~kg}$ of booster. 


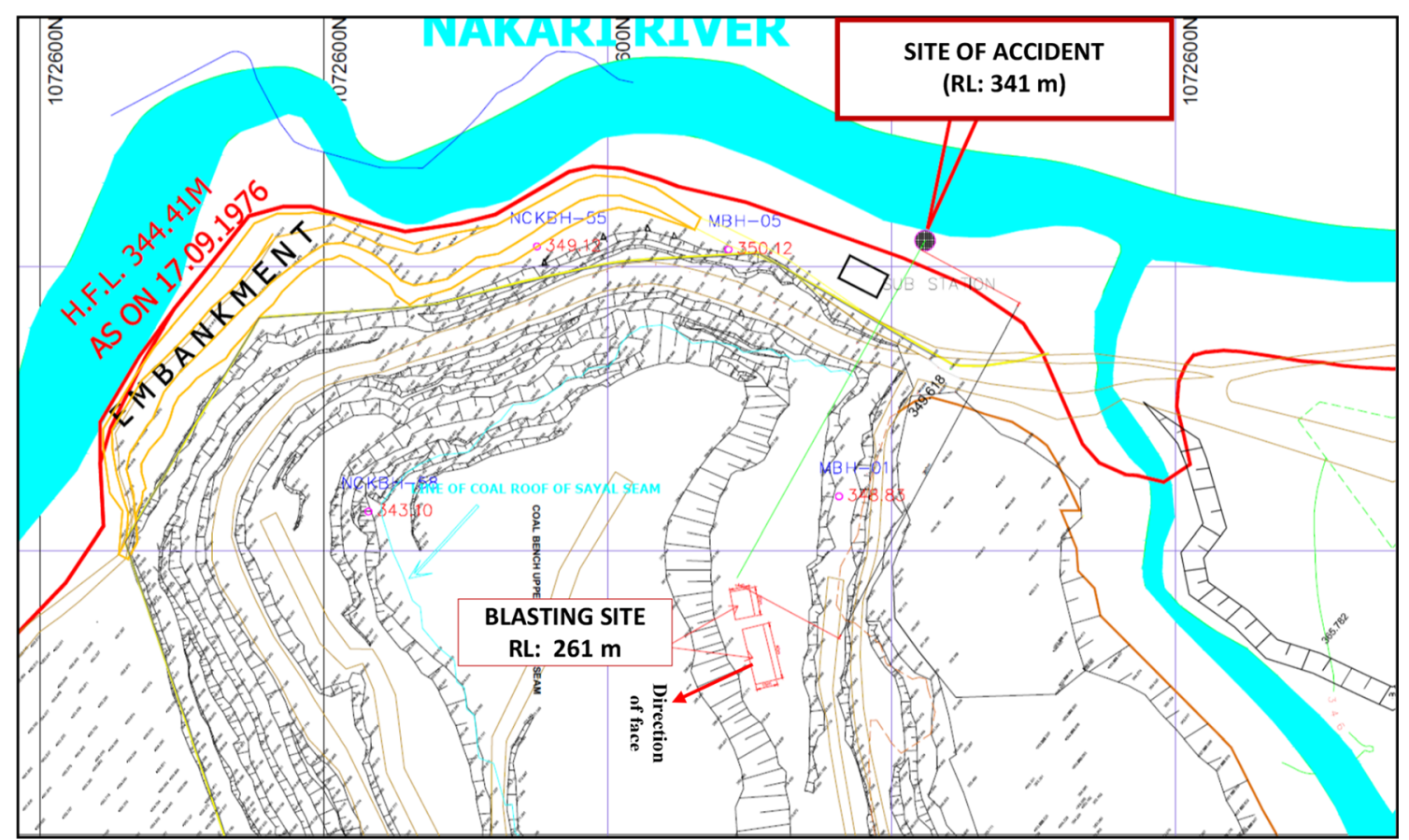

Fig. 1 Location of the blast and site of accident due to flyrock

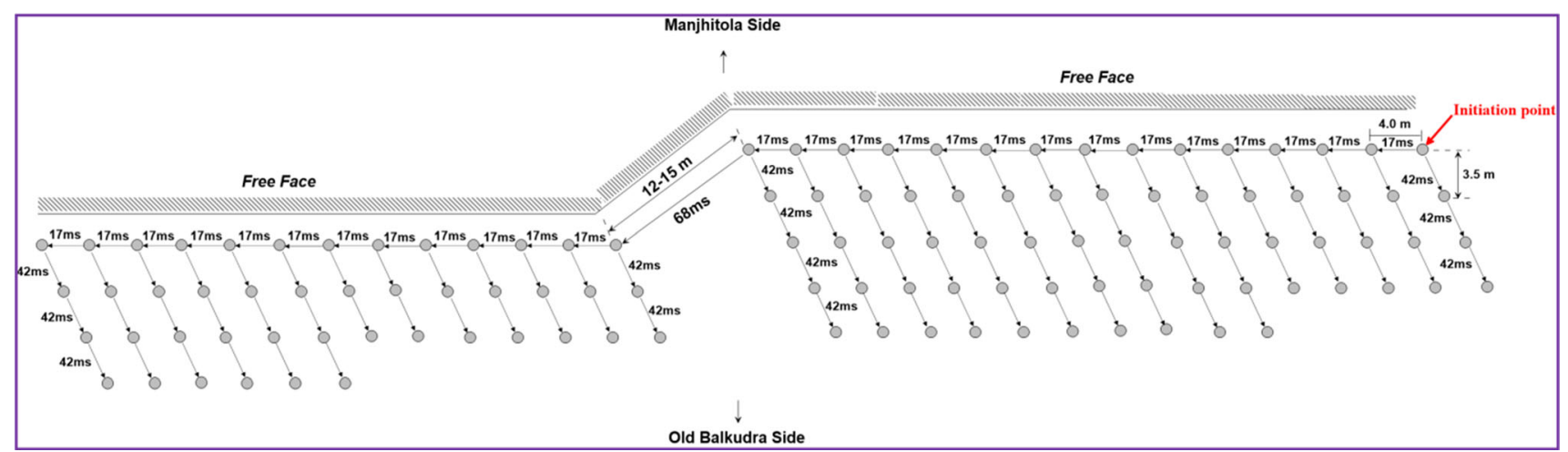

Fig. 2 Drilling and surface firing pattern of holes in the blasting operation conducted on 5th April 2017 where fatal accident occurred due to flyrock

\section{The Synonymous Blast}

In order to replicate the blast where flyrock accident occurred, a synonymous blast was conducted to study the possible causes of flyrock. The blasting event was recorded with a digital video camera to observe the rock movement and any occurrence of flyrock. The synonymous blast was conducted in OB Bench No. 6 (above Upper Balkudra Seam) consisting of sandstone and shale strata. Similar blast design parameters which were used in the blasting operation where the fatal accident occurred was tried to replicate in the synonymous blast. However, the number of holes and the exact nature of blast could not be replicated as blasting was conducted in the lower bench. But, blasthole diameter, explosive charge per hole, in-hole explosive initiation, surface hole-to-hole firing patterns were kept same. No muffling arrangement was done in the synonymous blast. The blast design parameters used in the synonymous blast and the blast in which flyrock occurred are given in Table 2.

In order to study the firing sequence of holes, direction of burden movement, maximum number of holes and maximum charge per delay detonated within $8 \mathrm{~ms}$ window, the synonymous blast was simulated using JK SimBlast Software of M/s Soft-Blast Private Limited. The drilling and surface firing patterns of holes generated in JK SimBlast are shown in Fig. 3. The firing sequence of holes along with time contour and maximum charge per delay and burden relief are shown in Figs. 4 and 5. 
Table 2 Blast design parameters used in the blast in which flyrock occurred and in the synonymous blast

\begin{tabular}{|c|c|c|}
\hline Blast design Parameters & Blast where flyrock accident occurred & Synonymous blast \\
\hline Location of the blast & OB Bench No. 3 & OB Bench No. 6 \\
\hline Nature of strata & Medium hard sandstone mixed with shale & Medium hard sandstone mixed with shale \\
\hline Presence of water inside the holes & Nil & Nil \\
\hline Condition of the face & Clear free faces & $\begin{array}{l}\text { Choked face at few area due to previous blasted } \\
\text { mucks }\end{array}$ \\
\hline Blasthole diameter & $160 \mathrm{~mm}$ & $160 \mathrm{~mm}$ \\
\hline Total number of holes & $\begin{array}{l}115 \text { (Patch 1: 45; Patch 2: 70) } \\
\text { Distance between two patches: } 15 \mathrm{~m} \\
\text { (Same bench) }\end{array}$ & $\begin{array}{l}105 \text { (Patch 1: 35; Patch 2: 70) } \\
\text { Distance between two patches: } 30 \mathrm{~m} \\
\text { (Same bench) }\end{array}$ \\
\hline Average depth of hole & $6.0 \mathrm{~m}$ & $6.0 \mathrm{~m}$ \\
\hline Burden & $3.5 \mathrm{~m}$ & $3.5 \mathrm{~m}$ \\
\hline Spacing & $4.5 \mathrm{~m}$ & $4.5 \mathrm{~m}$ \\
\hline Top stemming length & $\begin{array}{l}3.55-3.80 \mathrm{~m} \\
\text { Stemming material—drill cuttings }\end{array}$ & $\begin{array}{l}3.55-3.80 \mathrm{~m} \\
\text { Stemming material—drill cuttings }\end{array}$ \\
\hline Explosive charge per hole & $50.00 \mathrm{~kg}$ & $50.00 \mathrm{~kg}$ \\
\hline Total explosive charge & $\begin{array}{l}5767.25 \mathrm{~kg} \\
(5750 \mathrm{~kg} \mathrm{SME}+17.25 \mathrm{~kg} \text { Booster })\end{array}$ & $\begin{array}{l}5265.75 \mathrm{~kg} \\
(5250 \mathrm{~kg} \mathrm{SME}+15.75 \mathrm{~kg} \text { Booster })\end{array}$ \\
\hline Maximum charge per delay & $250.572 \mathrm{~kg}$ & $250.572 \mathrm{~kg}$ \\
\hline Explosive type & $\begin{array}{l}\text { SME (Bulk); Solar India Industries Ltd. (BE- } \\
\text { 101) } \\
\text { Density before gassing: } 1.35 \mathrm{~g} / \mathrm{cc} \\
\text { Density after gassing: } 1.10 \mathrm{~g} / \mathrm{cc}\end{array}$ & $\begin{array}{l}\text { SME (Bulk); Solar India Industries Ltd. (BE-101) } \\
\text { Density before gassing: } 1.35 \mathrm{~g} / \mathrm{cc} \\
\text { Density after gassing: } 1.10 \mathrm{~g} / \mathrm{cc}\end{array}$ \\
\hline Booster type & Emulsion $150 \mathrm{gm}$ & Emulsion $150 \mathrm{gm}$ \\
\hline In-hole initiation system used & DTH: $250 \mathrm{~ms}$ & DTH: $250 \mathrm{~ms}$ \\
\hline $\begin{array}{l}\text { Surface hole-to-hole initiation system } \\
\text { used }\end{array}$ & TLD: $17 \mathrm{~ms}$ and $42 \mathrm{~ms}$ & TLD: $17 \mathrm{~ms} \& 42 \mathrm{~ms}$ \\
\hline Muffling arrangement & No muffling & No muffling \\
\hline
\end{tabular}

\section{Observations from the Synonymous Blast}

No flyrock was observed and recorded in the synonymous blast conducted to replicate the actual blast which resulted into flyrock accident. However, ejection of finer particles from the stemming portion has gone up to a vertical height of about $75 \mathrm{~m}$, but limited within the blasting area only. The blasted materials were also confined to the blasting area only. The event sequences of the synonymous blast are shown in Fig. 6a-f.

\section{Assessment of the Possible Reasons of Flyrock Incidence}

In order to assess the possible reason for the occurrence of flying fragment projecting up to $280 \mathrm{~m}$, different approaches have been made based on the blast design parameters and patterns submitted by the mine management, nature of rock strata in the mine and the synonymous blast conducted in the mine.

\section{Analysis of the Blast Design Pattern Submitted}

The blast design patterns submitted by the mine management was simulated using JK SimBlast Software to study the firing sequence of hole, direction of burden movement, number of holes detonated within $8 \mathrm{~ms}$ window, maximum charge per delay and the burden relief. The charging pattern and in-hole explosive initiation pattern of holes obtained from the analysis software are given in Fig. 7. The charge length obtained for $50 \mathrm{~kg}$ of explosive charge per hole was $2.169 \mathrm{~m}$. The minimum top stemming column length for $6 \mathrm{~m}$ depth of hole $160 \mathrm{~mm}$ diameter was $3.75 \mathrm{~m}$, which was obtained in actual charging time. The stemming column was sufficient to hold the explosive charge inside the blast hole during the process of detonation. The spacing and burden ratio was around 1.28 which was quite adequate for a normal bench blasting. 


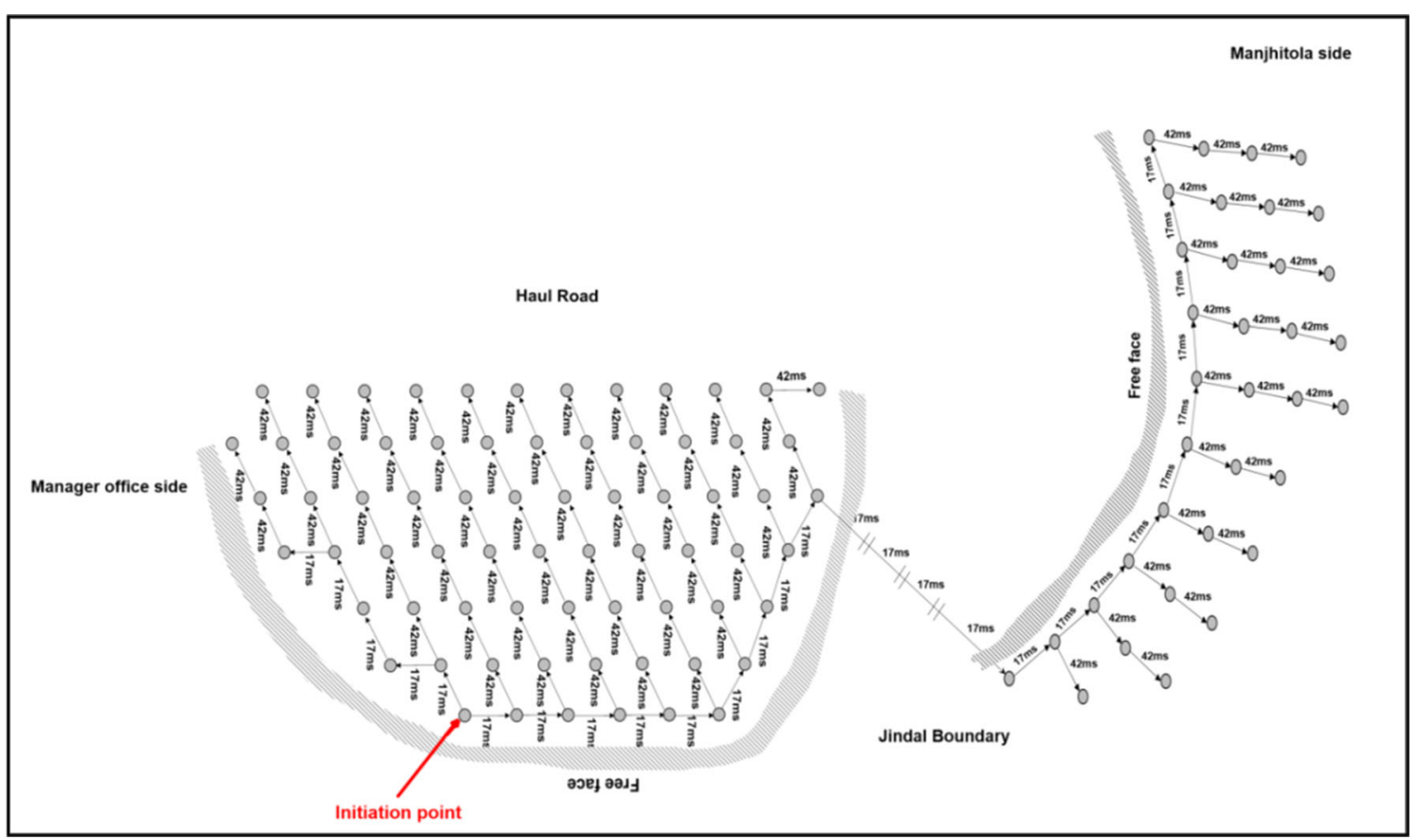

Fig. 3 Drilling and surface firing patterns of holes used in the synonymous blast

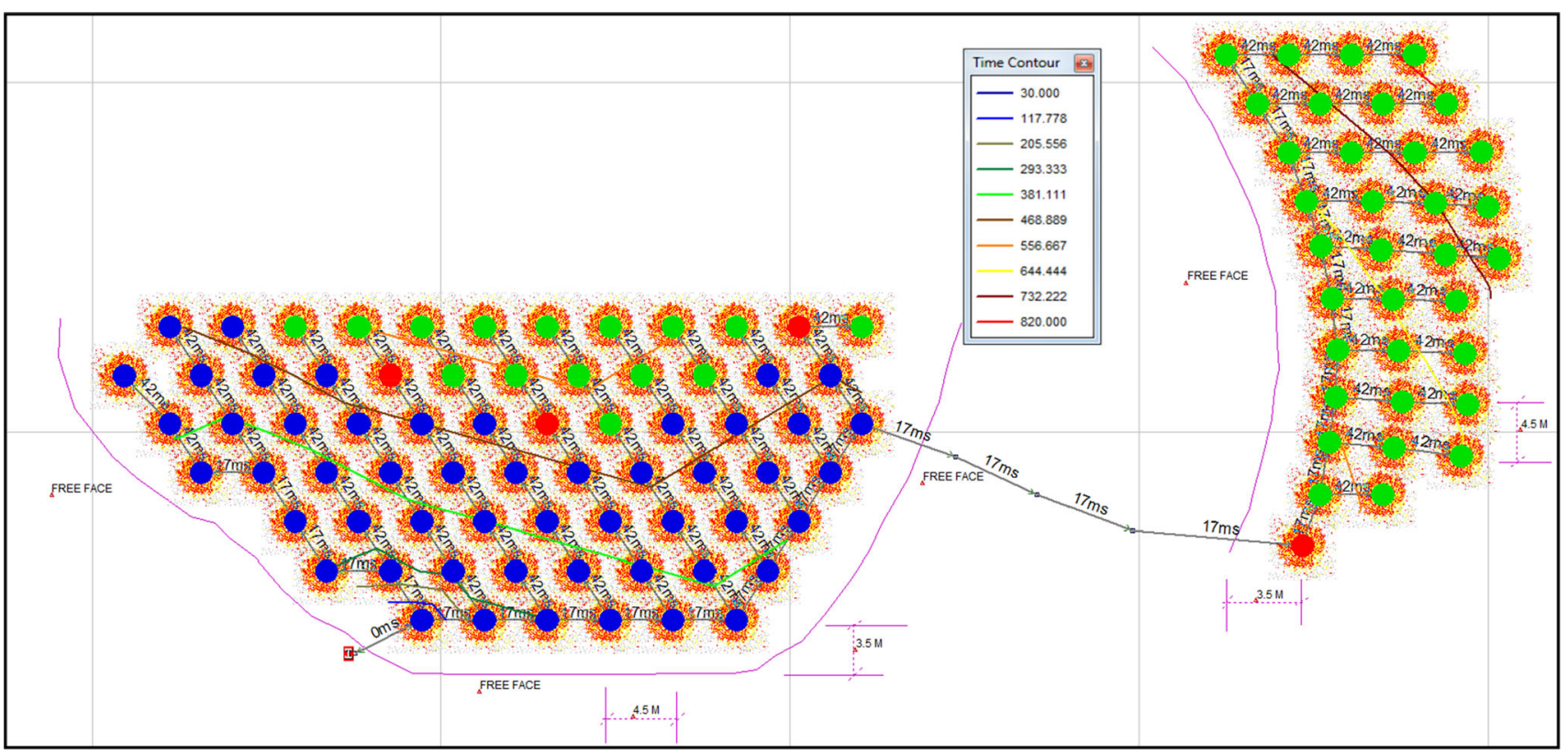

Fig. 4 Firing sequence of holes and time contour obtained using JK SimBlast

Based on the simulation results of the blast, the direction of rock movement within $83.33 \mathrm{~ms}$ interval was wide diagonal, without any abnormal line (Fig. 8). The maximum charge per delay obtained was $200.60 \mathrm{~kg}$ where four holes were fired within $8 \mathrm{~ms}$ (Fig. 9). Burden for the holes in 2nd and 3rd rows nearby the initiation point of the second patch was large resulting into more confinement (marked in circle in Fig. 8). This could hinder burden movement for the 2nd and 3rd row of holes located nearby the marked circle in the figure. The insufficient burden movement could result crater formation which in turn can cause flyrock generation in vertical direction. However, the success rate of burden relief in the blast was more than $80 \%$ and also top stemming column length more than the burden was used for all the holes. The inter-row delay period of $42 \mathrm{~ms}$ was also sufficient for the burden 


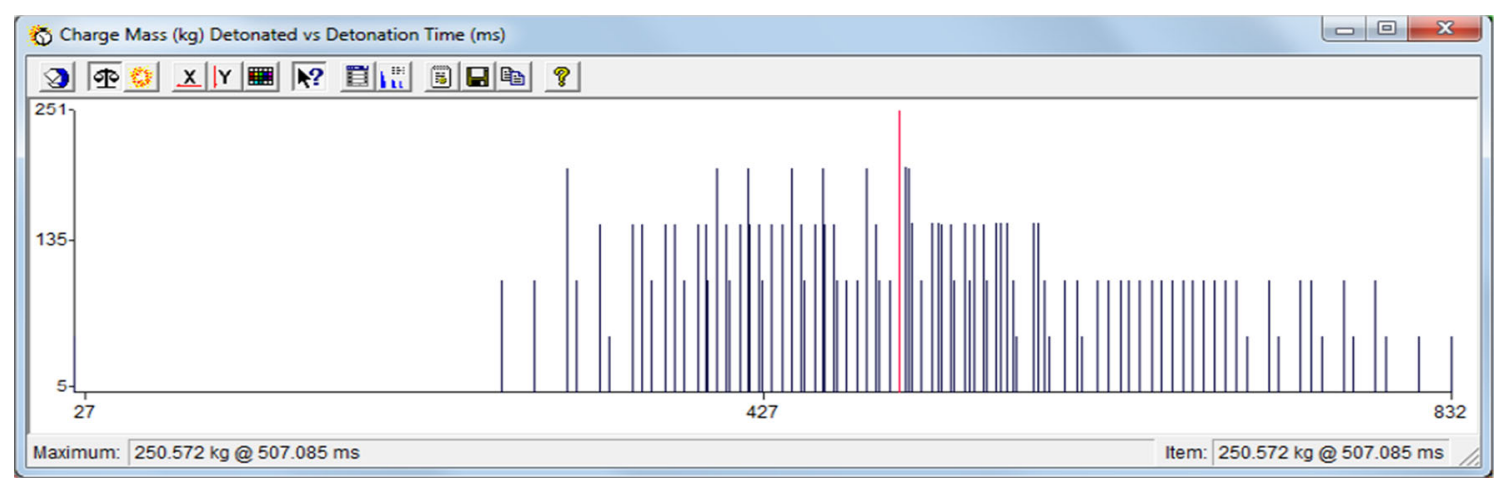

Fig. 5 Maximum charge per delay obtained along with the detonation time in the synonymous blast using JK SimBlast

Fig. 6 Event sequences of the synonymous blast conducted at the mines. a Initiation of holes started, b All holes initiated, some rock movement started, c All holes rock movement started, d Peak movement of the rock,e Last stage of rock movement, f Rock movement stopped
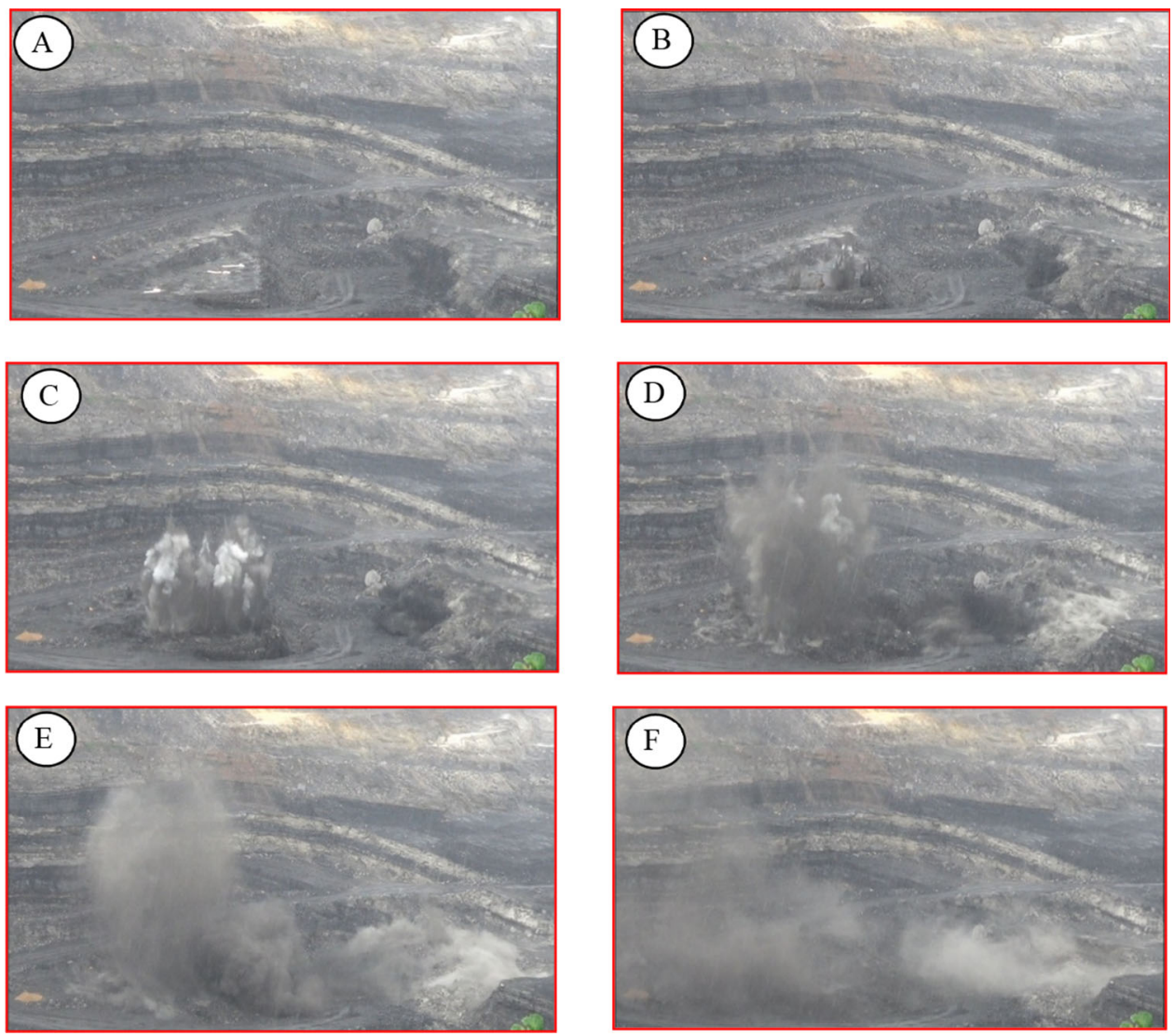
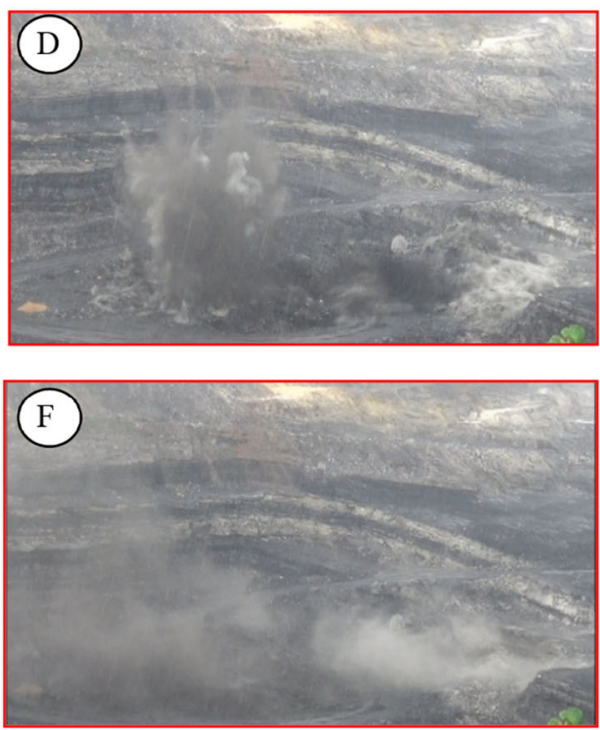

movement as the number of rows in the blast was only five. Therefore, the possibility of flyrock from the back portion of the blasting face due to insufficient burden movement (i.e., inadequate delay timing) and crater formation can be ruled out unless weak and fractured rock were present in the top portion of the holes. However, no information was given by the mine management regarding the strata condition of the blasting face. Hence, based on the simulation results of the blast design submitted by the mine management, it is difficult to assess the exact reason for the occurrence of flyrock.

\section{Based on Flyrock Prediction Models}

Based on the flyrock model developed by Lundborg et al. [3], the maximum flyrock range is $227 \mathrm{~m}$ for the blast conducted on 5th April 2017 in which flyrock accident occurred. Similarly, based on the maximum flyrock range as developed by Richard and Moore [5] for cratering mechanism, the maximum flyrock travel distances are $81 \mathrm{~m}, 126 \mathrm{~m}$ and $181 \mathrm{~m}$ for taking rock constant values of 20, 25 and 30, respectively. For face burst mechanism, the maximum flyrock range for the different site constants comes to $92 \mathrm{~m}, 144 \mathrm{~m}$ and $208 \mathrm{~m}$. 
Fig. 7 Charging and in-hole explosive initiation patterns of the blast
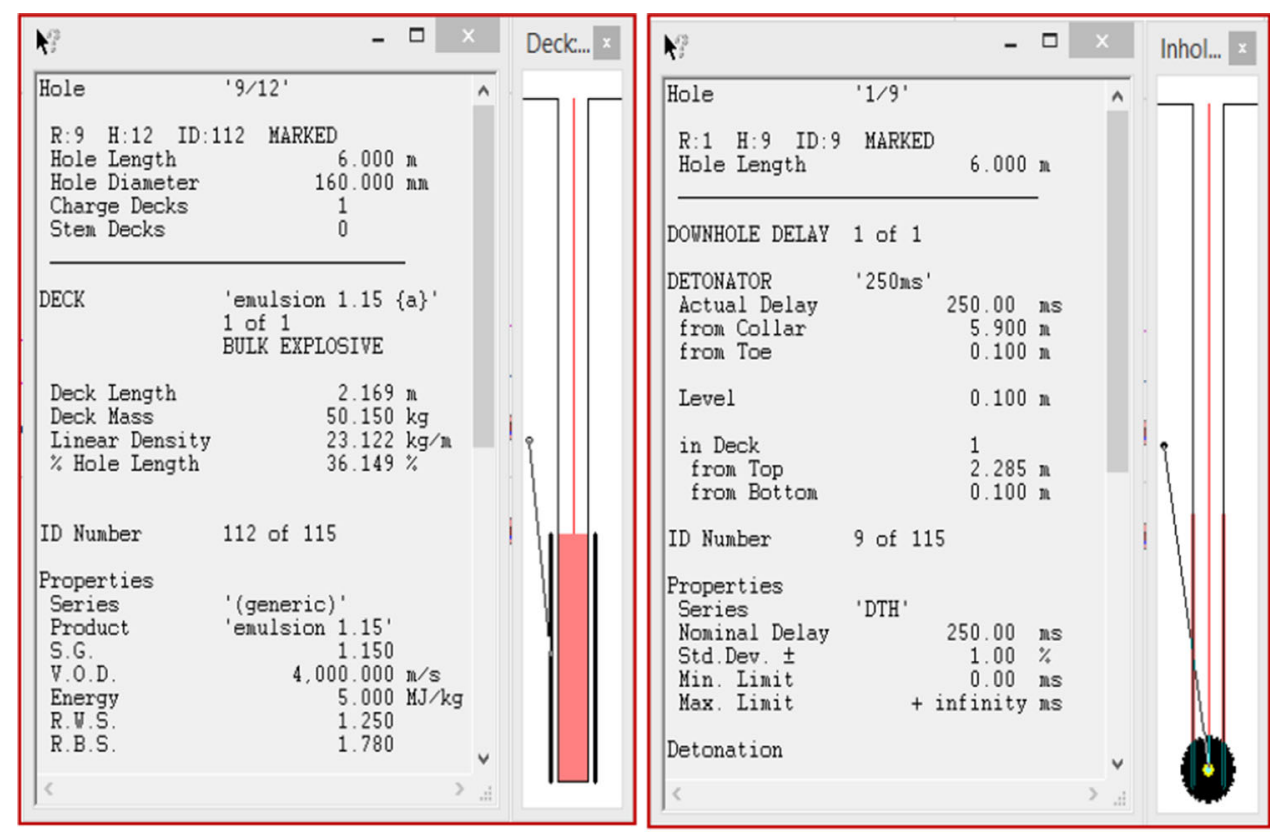

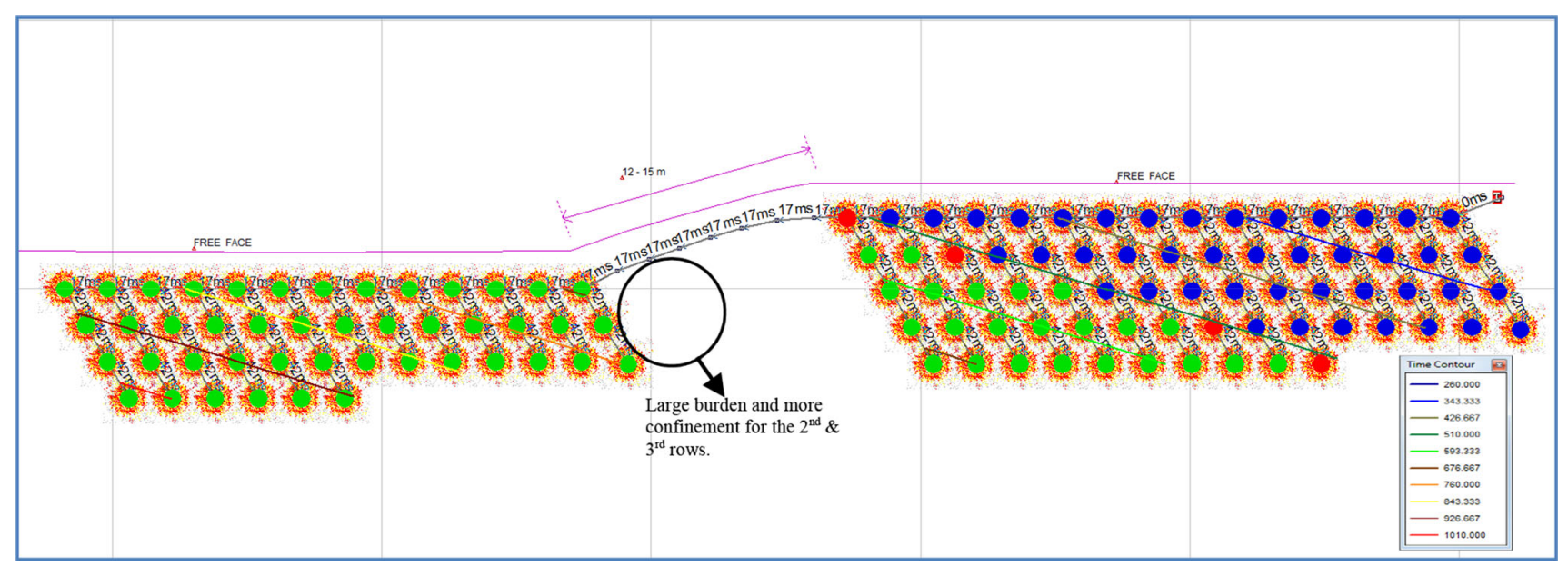

Fig. 8 Direction of rock movement with time contour obtained in the blast where flyrock accident occurred

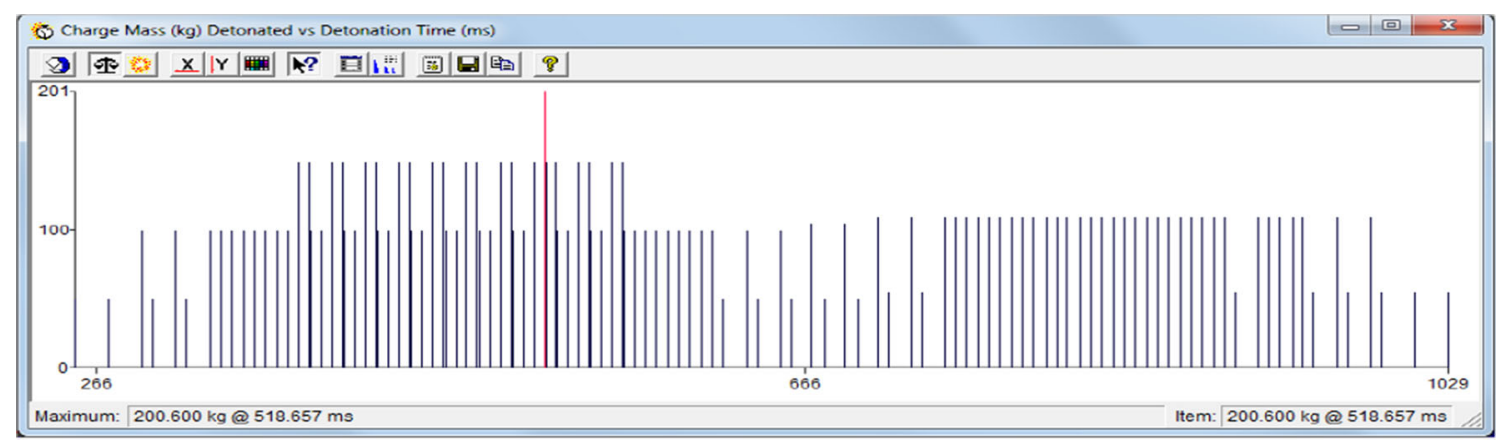

Fig. 9 Maximum charge per delay obtained from the blast where flyrock accident occurred

Based on the flyrock model developed by McKenzie (2009), the maximum flyrock distance comes to $147 \mathrm{~m}$ with the estimated size of the particle capable of achieving maximum projection distance value as $108 \mathrm{~cm}$. Therefore, on the basis of the analysis of the blast design patterns submitted by the mine management, flying fragments may 
not be able to travel up to $280 \mathrm{~m}$ distance if the blast design patterns are truly followed.

\section{Based on the Synonymous Blast}

In the synonymous blast, no flying fragments were observed and recorded which travelled up to a distance of more than $100 \mathrm{~m}$. Only vertical throw of the materials was observed and recorded. The maximum possible flyrock distances predicted by different researchers were also not matching as in the case of synonymous blast. One of the main reasons for flyrock occurrence is excessive charging of explosives. The charge factor used in both the synonymous blast and the blast in which flyrock occurred was same, i.e., $0.529 \mathrm{~kg} / \mathrm{m}^{3}$. The fragmentation obtained in the synonymous blast was good and no excessive rock breakages observed. The charge factor was sufficient for achieving proper fragmentation. Therefore, the reason for the occurrence of flyrock incident could not be assessed as flyrock was controlled in the synonymous blast and there was no any abnormal flyrock incidence in the blast.

\section{Based on the Nature of Rock Strata}

The different working benches of the overburden rock strata of the mine consist of medium hard sandstone, shale and shaly sandstone. Shale rock strata are jointed in nature, whereas medium grained sandstone is massive in nature (Figs. 10, 11). The thickness of the sandstone beds varied from 0.67 to $2.31 \mathrm{~m}$. Shale strata are located in the top and bottom portion of the bench. The thickness of shale strata in the top portion of the bench varied from 0.87 to $1.34 \mathrm{~m}$, whereas at the bottom of the bench, it varied from 2.51 to $2.89 \mathrm{~m}$. The mining operation was proceeding from the rise side to the dip side of the deposit. Blasting faces were

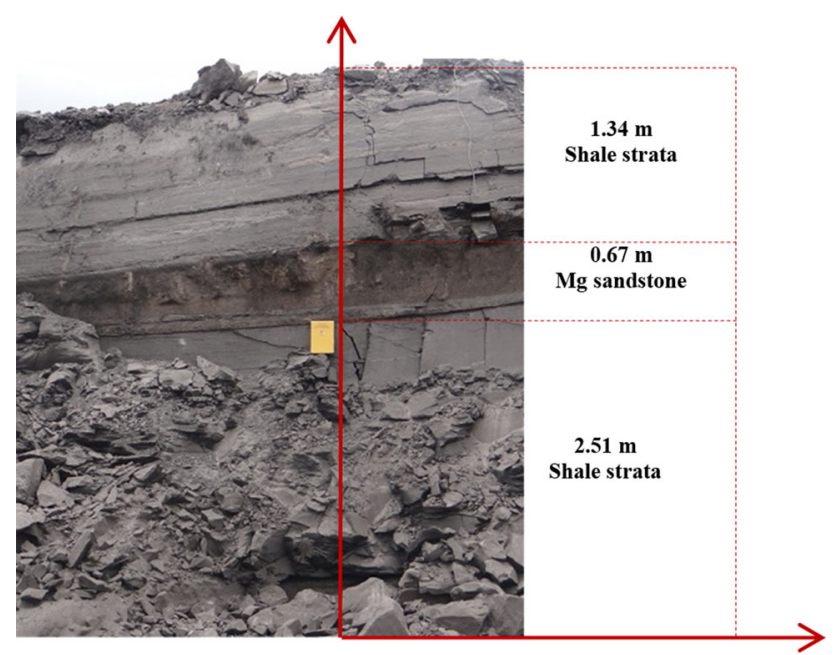

Fig. 10 View of shale rock strata in OB bench No. 3 mostly oriented towards the dip direction of the deposit. As the inclination of the rock deposit is 1 in 6 and the blasting faces were oriented towards the dip direction, thus the blastholes could encounter different strata formations at different levels.

Based on the site inspection, detailed study of blast design parameters and analyses of blast design patterns submitted by the mine management as well as observations of the synonymous blast, the only possible reason for the occurrence of flyrock on the fateful date where flying fragment travelled up to $280 \mathrm{~m}$ could be due to the anomaly in rock structures. Therefore, the only possible cause of flyrock occurrence was the presence of weak zone and abnormal strata from where flying fragment generated and travelled up to a distance of $280 \mathrm{~m}$ (CSIR-CIMFR Report [8].

\section{Recommended Procedure for Blast Design in Fractured Rock Strata}

The investigation results showed that presence of weak and fractured strata in the blasting rock masses was found to be the most possible cause of flyrock incident which resulted into fatal accident. Based on the study, the step-by-step procedure to design the blast in fractured/cracked formation and weak rock strata in order to avoid flyrock occurrence have been recommended as below.

\section{Planning of Drilling and Blasting}

In an opencast mine, drilling and blasting operations are generally planned based on the required production (targeted production) per day/month/year, nature of the rock

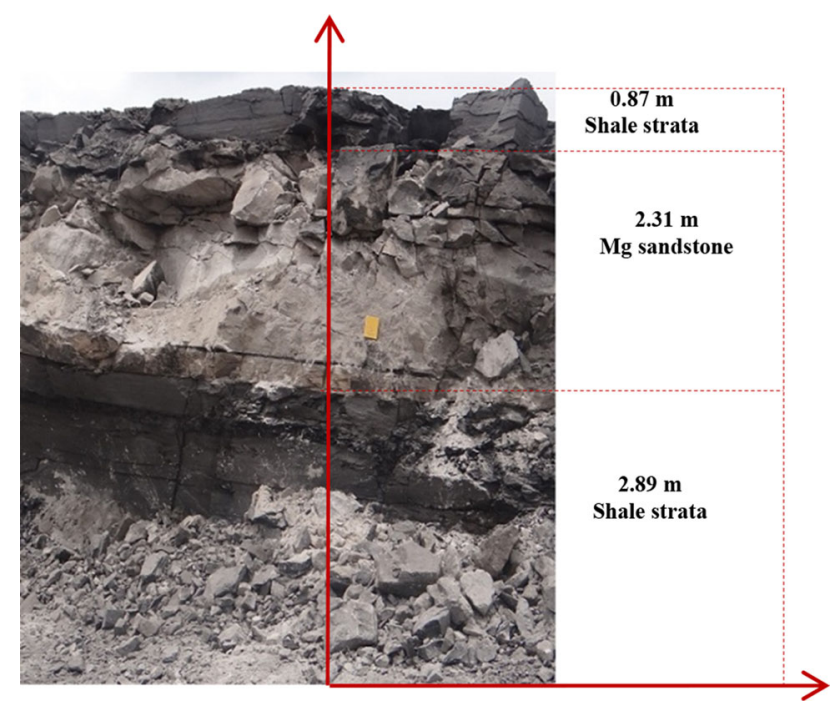

Fig. 11 View of the sandstone and shale strata in OB bench No. 3 
deposits (geology) and the possible environmental impacts created by blasting to the surrounding areas (sensitiveness). In case of blasting operations in fractured/cracked and disturbed rock formations where chances of flyrock are formidable, the followings should be considered for initial planning of drilling and blasting operations.

- Survey of the blasting benches

- Selection of blasthole diameter

- Selection of explosives and blasting accessories

- Sensitiveness of the area and provision of muffling arrangement

The entire area of blasting benches should be surveyed and inspected properly. The locations of different rock strata, their thicknesses and positions should be marked on the plan. The zones with weak and fractured strata should be clearly identified and located on the plan. The presence and extent of backbreak, endbreak, overbreak, overhang/ overcut at the face and undercut due to previous blasting should be identified carefully and marked. Image analysis method using digital photo analysis software will be very helpful for detailed joint survey of the blasting faces. Latest survey instruments such as laser profiler can also be very helpful to obtain the actual profile of the blasting benches. This will be very helpful to identify any overcut/undercut portions of the blasting faces and to design drilling pattern, particularly positioning of holes for the front row.

In general, smaller blast-hole diameter is preferable than larger diameter for flyrock control. Better blast fragmentation can also be achieved along with control on ground vibrations with smaller diameter of holes. Therefore, in fractured/cracked strata, blast-hole diameter of $100-115 \mathrm{~mm}$ is recommended than $160 \mathrm{~mm}$ diameter for hole depth of 5 to $6 \mathrm{~m}$. Blasthole diameter of 100-115 mm can effectively be used for hole depths up to $12 \mathrm{~m}$. Large diameter (LD) cartridge explosives are also more preferable than bulk explosives (SME/SMS explosives) in rock strata with heavily jointed formations and possibility of crack formations. Charging of holes can be controlled with LD explosives as they are carried out manually. Cracks/cavities can be easily noticed during loading of explosives inside the holes with manual charging and overcharging can be avoided which is often difficult in case of SME/SMS explosives. The use of either non-electric (nonel/shock-tube) initiation system or electronic detonators is strongly recommended for control on flyrock.

Sensitiveness of the area is mainly determined by the presence of residential houses and important surface and sub-surface structures nearby the blasting area. Muffling arrangement using blasting mats, wire-mess, conveyor belts, sandbags, etc., to control flyrock takes more time and generally people try to avoid it. However, it is always recommended to use muffling arrangements especially whenever residential houses and other important surface structures are located near to the blasting sites. Based on the present study, whenever blasting is to be conducted in fractured/cracked rock strata where the chances of flyrock are prominent, provision for muffling should be made in the initial planning of blasting operations.

\section{Design of the Blast}

The primary means for controlling flyrock is through proper blast design and careful implementation at the site. Blast design parameters viz. charge factor/specific charge (amount of explosive quantity required to break one cubic meter of rock, $\mathrm{kg} / \mathrm{m}^{3}$ ), burden, spacing, charging patterns (deck charging, top stemming column length), surface hole-to-hole firing patterns, etc., should be properly planned and decided based on the nature of the rock deposits, blasthole diameter to be used and the available bench height.

The number of rows in the blasting should be restricted and the length-to-width ratio of blasting area should not be less than 2.5. Bench height-to-burden ratio (stiffness ratio) should not be less than 2.5 as far as practicable and stiffness ratio less than 1.5 should be strictly avoided. The consistency of the burden, specially the front burden (distance between the first row to free face) must be maintained. The positioning of holes for the first/front row should be based on the face profile survey to avoid too less front burden or too more front burden due to overcut/ overhang from the previous blasts. The top stemming column length should be more than or equal to the burden value when the chance of flyrock occurrence is formidable.

Surface hole-to-hole firing pattern should be designed on the plan. Many blasting software are available to design the firing pattern of holes which is recommended to use for each blast. While designing firing pattern, effective burden, effective spacing, sequence of hole firing, direction of throw, timing for burden relief, etc., should be decided carefully to yield the best result.

\section{Drilling Operation}

The position of holes should be marked on the blasting bench and holes should be drilled as per the marking. Holes should not be drilled close to the cracks developed in the previous blasts. The drill operator should mark any possible presence of voids/cracks/cavities in the drilled holes during drilling operation and communicate the same to the charging crew. There should be good communications between the drilling operator and explosive charging crew which is often neglected in many mines. 


\section{Charging Operation}

Charging of holes with explosive is very important operation which required technical expert and experienced personnel. Drill holes in cracked/fractured rock strata have tendency to get choked and chances of cavity/crack formation inside the holes are also more. Therefore, the followings should be followed before, during and after charging operation of explosives in the holes.

- Drill cuttings near the collar of holes should be cleaned properly to prevent contamination of explosives by the drill cuttings during charging of holes.

- All the holes should be measured and marked their actual depths before charging of explosives. Borehole inspection camera, if available, should be used for inspection of all the holes to observe any crack/cavity/ opening inside the drilled holes.

- Presence of water inside the holes and water level should be checked and marked. The best way is to dewater all the holes before charging explosives.

- If any hole gets jammed/choked, it should be tried to get it cleared. If the blockage hole could not be cleared, it should be marked and should not be charged with explosives. If sufficient hole length is obtained above the blockage, plug the hole at the blockage portion and adjust the explosive quantity depend on the acquired depth.

- Cartridge explosives are recommended for blasting in cracked/fractured rock strata. If bulk explosives are used, possibility of accumulation of explosive charge in the cracks/cavity should be properly checked.

- It is a common practice to flush the charging pipe in the last hole in case of bulk explosive charging with pumptruck. This should be strictly avoided as it can cause over charging of hole.

- If the bench consists of mixed strata with hard and soft/ heavily jointed rocks, distribution of explosive charges using deck charging can be very effective to prevent excessive throw and flyrock from the soft/jointed rock portion. However, deck changing may not always possible particularly in shorter hole depth.

- In any case, overcharging of holes should be strictly avoided. Excessive charge factor should not be used and it should be optimum to achieve the desired fragment sizes, throw and heap of the blasted materials.

- Stemming of hole should be properly done using appropriate tamping rod. It is recommended to use stone chips, particularly if water are present inside the holes. However, the size of stone chips should be about $1 / 16 \mathrm{D}$ to1/25D (where $\mathrm{D}$ is diameter of holes).

\section{Surface Connection}

Before connecting the charged holes with surface hole-tohole initiation systems (TLDs-Trunk-line delays in case of Nonel or harness wire in case of electronic detonators), the surface area should be cleared off all the loose stones/ smaller boulders. The delays between holes and between rows should be assigned exactly as per the pre-planned firing pattern. Sometimes, it was observed that the surface hole-to-hole connections are made very tight, particularly in case of TLDs. Tight connection of TLDs on the surface can create misfire during burden movement resulting into cutoff of the surface connections.

If muffling is done, care should be taken while covering the surface area with muffling materials. The surface connection should not be disturbed, particularly the truckline delay detonators.

\section{Clearance of the Area}

Failure to clear/evacuate the blasting area is one of the main reasons for the occurrence of accident due to flyrock. The area within the danger zone of $500 \mathrm{~m}$ radius of the blasting site, as specified by the DGMS should be properly cleared. If any person is present within the danger zone, it should be made sure before firing of the shot that they have taken proper shelter. Any other security and safety measure as specified in the regulations should be followed strictly.

\section{Evaluation of the Blast Results}

Evaluation of the blast results is very important as the interpretation of the result will give the required modifications/changes to be made for the next successive blasts. The following three points are recommended for evaluation of blast results in view of flyrock control.

- Recording of the blasting event using high-speed video camera to identify and evaluate the source, reason and extent of flyrock. If high-speed video is not available, recording the blasts using normal video or even a mobile phone camera from a safe distance and safe location can be very useful.

- Evaluation on the presence and extent of back-break, end-break, over cut, undercut and toe-formation after clearance of the blasted materials.

- Occurrence of misfire (if any) and its reason should also be evaluated carefully. Re-firing of misfired hole/holes can generate uncontrollable flyrock. 


\section{Conclusions}

The investigation revealed that it was difficult to find out the exact reason for the occurrence of flying fragment travelling up to a distance of $280 \mathrm{~m}$ from the place of blasting based on the post-blast analysis. According to the flyrock prediction models developed by the different researchers, the maximum possible flyrock range as per the blast design parameter used was $227 \mathrm{~m}$. No abnormality was also found in the blast design parameters viz. burden, spacing, charge per hole, top stemming column length, delays used in the hole, surface firing pattern, etc., and these have been practiced regularly in the mine. In the synonymous blast conducted using the same blast design parameter where flyrock incident had occurred, no flying fragments were observed and recorded which travelled up to a distance more than $100 \mathrm{~m}$. The maximum possible flyrock distance predicted by the different researchers also did not match the flyrock distance recorded in the synonymous blast.

The only anomaly found in the blasting pattern where flyrock occurred was conducting two patches in a single round where large confinement (larger burden) was observed in the second patch of blasting. The insufficient burden movement could result in crater formation which can cause flyrock generation in vertical direction. However, the success rate of burden relief in the blast was more than $80 \%$ and the top stemming column length was more than the burden. Therefore, the only possible flyrock occurrence in the blast was found to be the presence of weak strata/fractured rock mass in the top stemming column zone causing uncontrolled vertical movement of flying fragments due to crater formation. Based on the investigation results, a step-by-step procedure for conducting a blast in fractured/cracked/jointed strata is recommended to avoid occurrence of flyrock in bench blasting.

Open Access This article is licensed under a Creative Commons Attribution 4.0 International License, which permits use, sharing, adaptation, distribution and reproduction in any medium or format, as long as you give appropriate credit to the original author(s) and the source, provide a link to the Creative Commons licence, and indicate if changes were made. The images or other third party material in this article are included in the article's Creative Commons licence, unless indicated otherwise in a credit line to the material. If material is not included in the article's Creative Commons licence and your intended use is not permitted by statutory regulation or exceeds the permitted use, you will need to obtain permission directly from the copyright holder. To view a copy of this licence, visit http://creativecommons.org/licenses/by/4.0/.

\section{References}

1. Coal Mines Regulation, Regulation No. 170(1-A) (b) (1957)

2. Coal Mines Regulation, Regulation No. 196 (2) (b) (2017)

3. N. Lundborg, The hazards of flyrock in rock blasting. Swedish Detonic Research Foundation, Reports DS 12, Stockholm (1974)

4. C.K. McKenzie, Flyrock range and fragmentation size prediction, in Proceedings of the 35th Conference on Explosives and Blasting Technique, Vol. 2, (2009) ISEE

5. A.B. Richards, \& A.J. Moore, Flyrock control-by chance or design, in ISEE conference, New Orleans (2002)

6. T.N. Little, Flyrock risk, in Proceedings of 30th ISEE conference on explosives and blasting technique, New Orleans, Louisiana (2007), pp. 35-43

7. A.K. Raina, V.M.S.R. Murthy, A.K. Soni, Estimating flyrock distance in bench blasting through blast induced pressure measurements in rock. Int. J. Rock Mech. Min. Sci. 76, 209-216 (2015)

8. CSIR-CIMFR Report, Study to find out the reason for flying fragments during an accident on 05.04.2017 at Balkudra Outsourcing Patch, M/S CCL, Barka-Sayal area of Bhurkunda 'A' Colliery, Ramgarh, Jharkhand [CNP/4596/2017-18] (2017), p. 28

Publisher's Note Springer Nature remains neutral with regard to jurisdictional claims in published maps and institutional affiliations. 